ERRATUM

\title{
Prevalence of mental disorders in non-demented elderly people in primary care - ERRATUM
}

Luisa Baladón, Ana Fernández, Maria Rubio-Valera, Jorge Cuevas-Esteban, Diego J. Palao, Juan A. Bellon and Antoni Serrano-Blanco

doi: 10.1017/S1041610214002841, Published online by Cambridge University Press, 3 February 2015

In the above mentioned article by Baladón et al. (2015), an error has been introduced in the title of the article.

This error has now been rectified in the online and print version of the article.

\section{Reference}

Baladón, L., Fernández, A., Rubio-Valera, M., Cuevas-Esteban, J., Palao, D. J, Bellon, J.A and Serrano-Blanco, A. (2015) Prevalence of mental disorders in non-demented elderly people in primary care. International Psychogeriatrics, 27, 757-768. doi: 10.1017/S1041610214002841 